\title{
Scintigraphic measurement of gastric emptying and ultrasonographic assessment of antral area: relation to appetite
}

\author{
K Hveem, K L Jones, B E Chatterton, M Horowitz
}

\begin{abstract}
Background-Ultrasound measurement of gastric emptying has potential advantages over scintigraphy, but there is little information about its accuracy.

Aims-The relation between ultrasonographic measurements of antral area and (a) scintigraphic measurements of gastric emptying and intragastric distribution of liquids (b) postprandial satiation, were evaluated.
\end{abstract}

Subjects-Seven normal volunteers were studied.

Method-Each subject drank $75 \mathrm{~g}$ dextrose dissolved in $350 \mathrm{ml}$ of water $(300 \mathrm{kcal})$ or beef soup ( $20 \mathrm{kcal})$, both labelled with technetium-99m sulphur colloid on separate days and had measurement of gastric emptying by scintigraphy and ultrasound. Results-Scintigraphic and ultrasound $50 \%$ emptying times (T50s) were comparable and longer $(p<0.001)$ for dextrose than soup mean (SEM) (dextrose 107 (16) min $v 108$ (18) $\min$, soup 24 (4) $\min v 23$ (5) $\mathrm{min}$ ). There were close correlations between scintigraphic and ultrasound T50s (dextrose $r=0.94, p<0.005$, soup $r=0.97, p<0.001)$ and between the time at which the distal stomach content decreased from its maximum value by $50 \%$ (measured scintigraphically) and the ultrasound T50 (dextrose $r=0.95, p<0.005$, soup $r=0.99, p<0.0001)$. In contrast, there was no significant relation between the distal stomach content when expressed as a percentage of the maximum content in the total stomach and the ultrasound T50. After dextrose, fullness was related $(r=0.92, p<0.01)$ to the postprandial increase in antral area measured by ultrasound.

Conclusions-Ultrasound measurements of gastric emptying are: (a) of comparable sensitivity to scintigraphy in quantifying emptying of both low and high nutrient liquids (b) correlate with postprandial satiation, suggesting that the latter may be mediated by antral distension.

(Gut 1996; 38: 816-821)

Keywords: gastric emptying, antral area, scintigraphy, ultrasound.

Although a number of methods have been used to assess gastric emptying in humans, ${ }^{1-6}$ many of these have technical limitations or are complex to perform. Scintigraphy is at present the 'gold standard' for clinical measurement of gastric emptying. ${ }^{16-8}$ Scintigraphy, however, requires expensive equipment that is often not readily available and is associated with a radiation burden. Real time ultrasound can be used to assess gastric emptying ${ }^{9-14}$ and has major advantages over other techniques in that it is non-invasive, does not entail radiation, and is widely available. Doppler ultrasound techniques permit evaluation of antral wall motion and transpyloric flow. ${ }^{1516}$ Because there have been few comparisons between ultrasound and scintigraphic techniques the precision and clinical utility of ultrasonographic measurement of gastric emptying remain uncertain. ${ }^{1} 17$

Using ultrasound, gastric emptying has characteristically been assessed by measurement of changes in antral cross sectional area ${ }^{1819}$ or diameter. ${ }^{12} 20$ The rate at which antral diameter decreases from the maximum achieved soon after a drink correlates with gastric emptying measured scintigraphically. ${ }^{11} 1314$ It is, however, uncertain why gastric emptying of liquids should be related to changes in antral area. In particular, emptying of liquids is dependent on the relation between motor events in the proximal stomach, antrum, pylorus, and small intestine, rather than the motor function of the proximal stomach alone. ${ }^{27}$ Antral width reflects the interplay of passive and active forces favouring distension (including intragastric volume, gravity, and fundic tone) and resistance to distension occurring as a result of muscular contractions. It is therefore potentially both a determinant of, and determined by, the content of the distal stomach. The factors that regulate emptying differ fundamentally between nutrient and non-nutrient liquids $^{2}$ - feedback from small intestinal luminal receptors predominates in the control of nutrient containing liquids, ${ }^{21} 22$ whereas gravity and intragastric volume are important determinants of emptying of isotonic liquids, which empty faster from the stomach than nutrient containing liquids. 2324 While the observed relation between ultrasound measurements of antral area and gastric emptying ${ }^{11} 1314$ suggests that the distal stomach, and in particular antral 'tone', has a role in regulating gastric emptying of liquids, gastric emptying of liquids is known to correlate with the content of the proximal stomach and not that of the distal stomach measured scintigraphically - that is, the proximal stomach usually 'empties' in parallel with the total stomach, whereas the distal stomach content initially increases and subsequently decreases. ${ }^{72}$ However, the possibility that there is a relation between emptying 
from the total stomach and the rate at which the antral content decreases - that is, antral content expressed as a percentage of its maximum, rather than the maximum content of the total stomach, has not been evaluated. We have therefore examined the relation between scintigraphic measurements of the content of the distal stomach, with ultrasound measurements of antral area after ingestion of low and high nutrient liquids.

The factors that regulate appetite in humans are complex, but it is clear that signals from the gastrointestinal tract are important. ${ }^{23-27}$ The relation between gastric emptying and postprandial hunger is, however, comparatively weak. ${ }^{23} 25$ It is possible that antral distension may itself contribute to satiation and this concept has been strengthened by recent findings in patients with non-ulcer dyspepsia that both fasting and postprandial antral area are often increased ${ }^{181928}$ and intragastric meal distribution is abnormal. ${ }^{29} \mathrm{We}$ have examined the relation between postprandial hunger and fullness and postprandial antral area in normal subjects.

\section{Methods}

Subjects

Seven healthy volunteers ( $3 \mathrm{~F}, 4 \mathrm{M}$ ) with a median age of 23 years (range 20-27) and body mass index of $22 \mathrm{~kg}^{-2}$ (range $16 \cdot 5-24 \cdot 7$ $\mathrm{kg}^{-2}$ ) were studied. None was taking medication, had gastrointestinal symptoms, or had any history of gastrointestinal disease. Smoking was prohibited on the morning of and during gastric emptying measurements.

\section{Protocol}

Simultaneous measurements of gastric emptying by scintigraphy and ultrasound were performed in each subject after ingestion of either a low or high nutrient drink on two separate days. After an overnight fast (14 hours for solids and 12 hours for liquids) subjects ingested $350 \mathrm{ml}$ of low nutrient beef soup $(20 \mathrm{kcal})$ or dextrose $(75 \mathrm{~g}$ dissolved in $350 \mathrm{ml}$ water, $300 \mathrm{kcal})$. The drinks were consumed at either $1000 \mathrm{am}$ or $200 \mathrm{pm}$, but at the same time of day for each subject. The time period separating the two test days was three to seven days. Gastric emptying was quantified scintigraphically ${ }^{67}$ and antral area by ultrasound. ${ }^{11-13}$ Feelings of hunger and fullness were assessed via a visual analogue scale administered immediately before ingestion of the drink and at regular intervals thereafter. ${ }^{23-25}$ Written informed consent was obtained from all subjects and the protocol was approved by the Ethics Committee of the Royal Adelaide Hospital.

\section{Scintigraphic measurement of gastric emptying} Details of this single isotope test, which measures total, proximal, and distal stomach emptying have been reported. ${ }^{22}$ Both the beef soup and the dextrose contained $20 \mathrm{MBq}$ of
$99 \mathrm{~m}$ Tc-sulphur colloid and were heated to $37^{\circ} \mathrm{C}$ immediately prior to ingestion. Subjects consumed the test drinks over one minute, and time zero was defined as the time of completion. Each study was performed with the subject seated with their back against the gammacamera (Siemens Basicam 300). Radionuclide data were acquired at a rate of one frame every 30 seconds for the first 30 minutes and thereafter in three minute frames until at least $90 \%$ of the drink had emptied, or for a maximum period of 180 minutes. Data were corrected for subject movement and radionuclide decay using previously described methods. ${ }^{67}$ Correction for gamma ray attenuation was performed using factors derived from a lateral image of the stomach. ${ }^{67} \mathrm{~A}$ region of interest (ROI) was drawn around the total stomach, which was subsequently divided into proximal and distal regions - the proximal region corresponding to the fundus and proximal corpus and the distal region representing the antrum and distal corpus. ${ }^{22}$ Gastric emptying curves for total, proximal, and distal stomach (representing $\%$ retention over time) were derived. Several parameters were obtained from the curves for subsequent statistical analysis. For the total, proximal, and distal stomach the retention of isotope every five minutes until 60 minutes (expressed as the \% of maximum counts in the total stomach) were derived. For the dextrose drink, which emptied more slowly than the soup, the amount remaining in each of these regions was also calculated every 10 minutes between $60-180$ minutes. The content of the distal stomach was also expressed as a percentage of its maximum. For the total stomach the lag phase before any liquid had left the stomach, and the $50 \%$ emptying time (T50) were also calculated. The lag phase was determined visually by the frame preceding that in which activity was first seen in the proximal small intestine. $^{6}$

Ultrasound measurement of antral area

Measurements of antral area were performed using a Diasonic DRF 400 Ultrasound Machine with a $5 \mathrm{MHz}$ sector transducer and real time images were stored on a video recorder. While the subject was seated with his or her back against the gammacamera, the ultrasound transducer was positioned in the region of the umbilicus. For evaluation of antral area, the transducer was positioned vertically to visualise the antrum in cross section with the superior mesenteric vein and the abdominal aorta in a longitudinal section. ${ }^{12} 19$ Antral area was measured using a built in calliper and calculation programme. ${ }^{19}$ The first measurement was performed within one minute after meal ingestion and was followed by images at five minute intervals for the first hour and 10 minute intervals thereafter, until $90 \%$ had left the stomach for a maximum of 180 minutes. Ultrasound T50 was defined as the time when antral area decreased to half its maximum. ${ }^{19}$ 


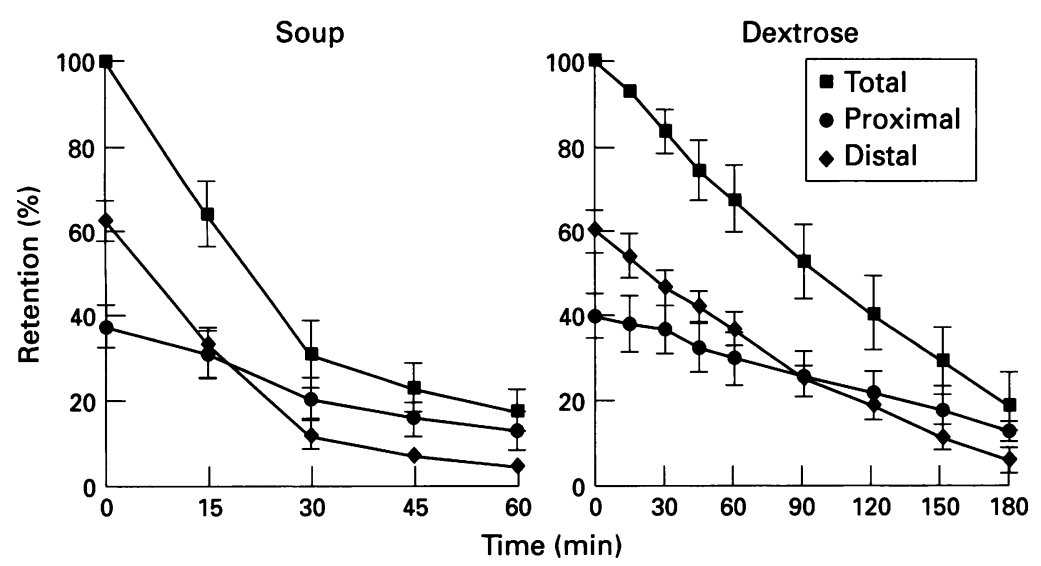

Figure 1: Retention of soup and dextrose in total, proximal, and distal stomach regions of interest. Data are mean (SEM) values.

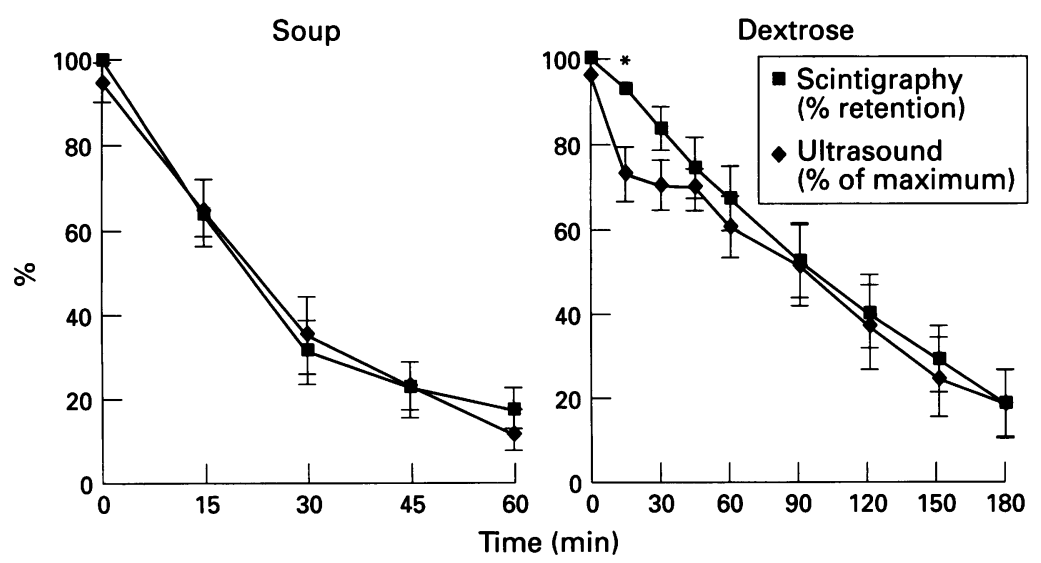

Figure 2: Gastric emptying of soup and dextrose measured scintigraphically (intragastric retention of isotope) and by ultrasound (changes in antral area). Data are mean (SEM) values.

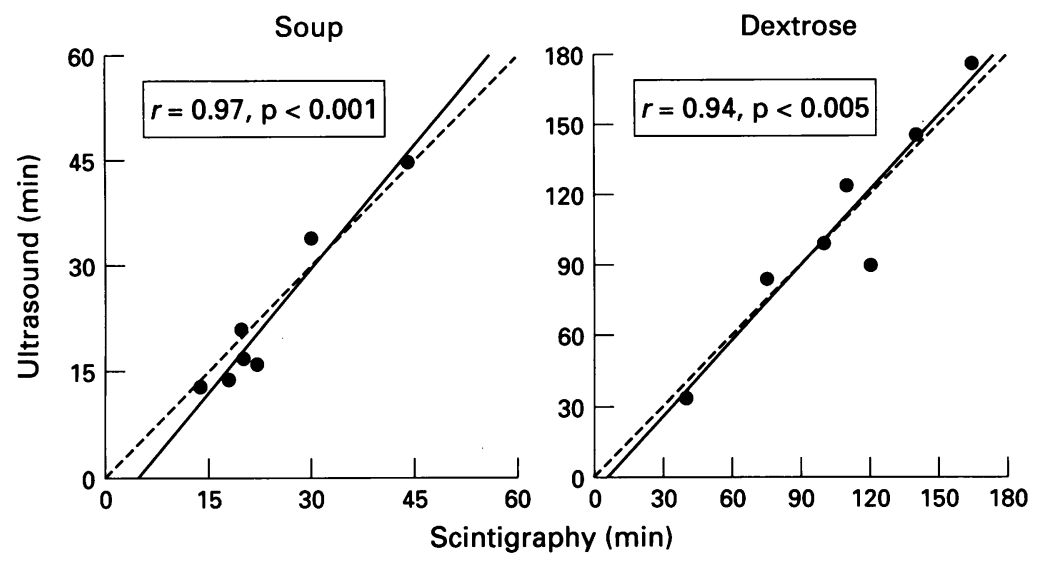

Figure 3: Relation between ultrasound and scintigraphic 50\% emptying times (T50) for soup and dextrose.
Statistical analysis

Data are presented as mean (SEM) values and were evaluated using repeated measures analysis of variance (ANOVA). Non-parametric comparisons between groups (T50, lag phase) were performed by the Wilcoxon rank sum test. Relations were assessed by linear regression analysis. The difference between scintigraphic and ultrasound T50s was plotted against the mean of the two methods (difference plot) ${ }^{3031}$ and limits of agreement were defined as the mean (2 SD) difference (\%). ${ }^{30} \mathrm{~A}$ $p$ value of $<0.05$ was considered significant in all analyses.

\section{Results}

All subjects tolerated the study well. The resolution of ultrasound images was satisfactory in all cases.

\section{Scintigraphic measurements of gastric emptying} and intragastric distribution

Gastric emptying of the soup was much faster than the dextrose (T50=22.9 (4.6) $\mathrm{min}$ $v 108 \cdot 1(17.5) \mathrm{min}, \mathrm{p}<0.001$ ) (Fig 1). After an initial lag phase $(0.9(0.2) \mathrm{min}$ for soup, 4.3 $(2 \cdot 2)$ min for dextrose, $p<0.05)$, emptying of soup approximated a mono-exponential function with a slope that decreased with time. In contrast, the emptying pattern of dextrose was linear. For both soup and dextrose the retention in the proximal stomach closely paralleled that for the total stomach, while the distal stomach content did not. The slower emptying of dextrose compared with soup from the total stomach was associated with increased retention in both the proximal stomach at 15 minutes $(p<0.05), 30$ minutes $(p<0.005)$, 45 minutes $(p<0.001)$, and 60 minutes $(\mathrm{p}<0.001)$ and the distal stomach at 30 minutes $(p<0.005), 45$ minutes $(p<0.001)$, and 60 minutes $(\mathrm{p}<0.005)$. For both drinks, the content of the proximal stomach was initially greater than that of the distal stomach, and subsequently more isotope was retained in the distal stomach. The content of the distal stomach was greater soon after completion of each drink.

\section{Relations and limits of agreement between} scintigraphic and ultrasound measurements Scintigraphic and ultrasound T50s were not significantly different $(22 \cdot 9(4 \cdot 6) \mathrm{min}$ and $24 \cdot 0$ (3.8) min for soup and 108.1 (17.5) $\mathrm{min}$ and $107 \cdot 3(15 \cdot 6) \mathrm{min}$ for dextrose) (Fig 2) and the overall scintigraphic and ultrasound curves for total stomach emptying were comparable. As assessed by ultrasound, emptying of dextrose was faster $(p<0.05)$ at 15 minutes (Fig 2). There was a close correlation between the scintigraphic total stomach $\mathrm{T} 50$ and ultrasound T50 for both dextrose $(r=0.94$, $\mathrm{p}<0.005)$ and soup $(r=0.97, \mathrm{p}<0.001)$ (Fig $3)$. For the $\mathrm{T} 50$ the limits of agreement were $+5.7 \mathrm{~min}(24 \%)$ and $-7.9 \mathrm{~min}(-41 \%)$ for the soup (mean difference $-1.1 \mathrm{~min}$ ) and $+32.5 \mathrm{~min}(30 \%)$ and $-30.7 \mathrm{~min}(-31 \%)$ for Complete details of this questionnaire have been given in previous publications. ${ }^{23-25}$ Subjects completed the questionnaire immediately before ingestion of the drinks and then at $15,30,45$, and 60 minutes (soup and dextrose) and also at 90 and 120 minutes for dextrose. 


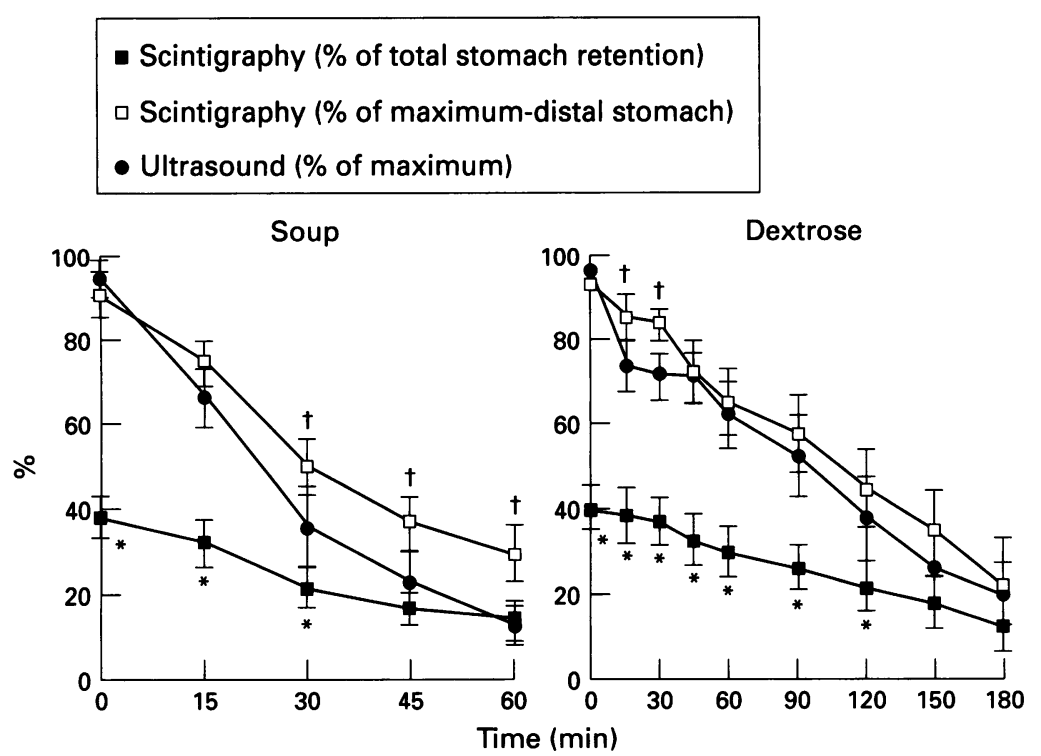

Figure 4: Retention in the distal stomach measured scintigraphically (expressed as the \% of the total stomach counts and \% of the maximum content of the distal stomach) and ultrasound measurements of changes in antral area, for soup and dextrose. Data are mean (SEM) values. ${ }^{\star} p<0.05$ scintigraphy $\mathrm{v}$ ultrasound.

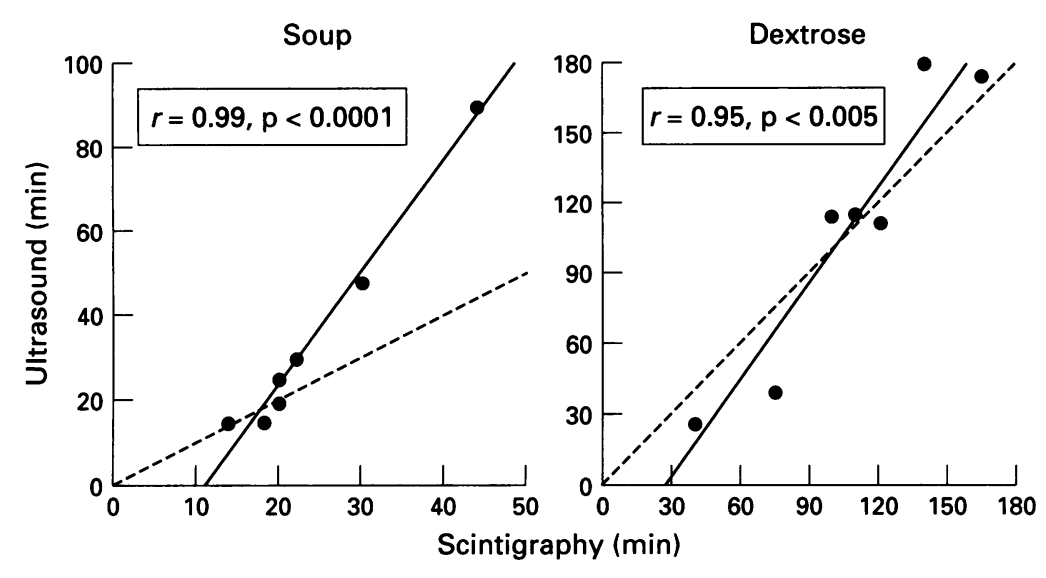

Figure 5: Relations between ultrasound T50 and the T50 for the distal stomach measured scintigraphically (expressed as the \% of the maximum content of the distal stomach) for soup and dextrose. dextrose (mean difference $0.9 \mathrm{~min}$ ). Limits of agreement were less than $\pm 15 \%$ for 10 of the 14 tests.

There was a poor relation between ultrasound measurements of antral area and scintigraphic measurements of the content of the distal stomach when the latter was expressed as a percentage of the maximum total stomach content (Fig 4). However, when the scintigraphic content of the distal stomach was expressed as a percentage of the maximum content of the distal stomach, rather than the total stomach, there was a much closer concordance (Fig 4), so that the time for the distal stomach content, measured scintigraphically to decrease to $50 \%$ of maximum correlated closely with the ultrasound T50 for both dextrose $(r=0.95, \mathrm{p}<0.005)$ and soup $(r=0.99$, $\mathrm{p}<0.0001$ ) (Fig 5).

\section{Hunger and fullness}

At 15 minutes hunger had decreased $(p<0.05)$ and fullness increased $(p<0.05)$ after ingestion of both dextrose and soup (Fig 6). Hunger tended to be less and fullness greater after dextrose than soup, but these differences were not significant. There were significant inverse relations between scores for hunger and fullness at 15 minutes $(r=-0.75, \mathrm{p}<0.05), 30$ minutes $(r=-0.77, \mathrm{p}<0.05)$, and 45 minutes $(r=-0.75, \mathrm{p}<0.05)$ for soup, but not dextrose.

\section{Relations between hunger, fullness, and gastric emptying}

There was no significant relation between postprandial hunger and scintigraphic or ultrasound measurements of gastric emptying for either soup or dextrose. In contrast, for dextrose but not soup, the score for fullness at 15 minutes was closely related to the magnitude of the postprandial increase in antral area measured by ultrasound $(r=0.92, \mathrm{p}<0.01)$ (Fig 7). At 60 minutes fullness was related to the content of the distal stomach measured scintigraphically $(r=0.75, \mathrm{p}<0.05)$ but not to total stomach emptying.

\section{Discussion}

We have shown in normal, healthy subjects that (a) there is a close correlation between scintigraphic measurements of total stomach emptying of liquids and changes in antral area and (b) postprandial fullness is related to the retention of dextrose in the distal stomach when measured by either scintigraphy or ultrasound.

In considering the potential use of ultrasound compared with scintigraphy, for measurement of gastric emptying for clinical and research purposes, it is essential that the limits of agreement between the two techniques are acceptable. A number of different methods to measure the size of the antrum by ultrasound have been used to calculate the rate of gastric emptying, including the volume, ${ }^{9}$ cross sectional diameter, product of two diameters, ${ }^{12}$ and parasagittal or longitudinal 


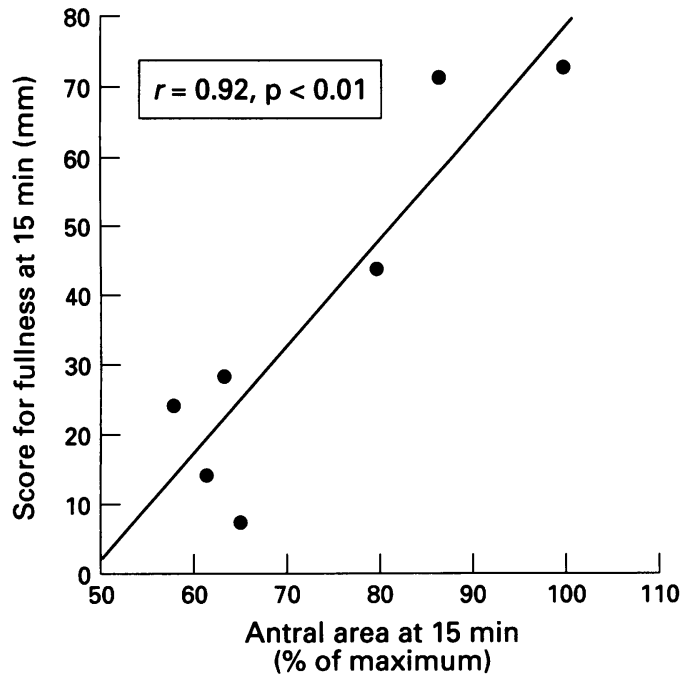

Figure 7: Relation between the score for fullness and the change in antral area measured by ultrasound 15 minutes after ingestion of dextrose.

area. ${ }^{18}$ The previous finding of a close relation between rates of gastric emptying of liquids measured by scintigraphy and many of these measures $^{11} 1314$ has formed the basis of the assertion that ultrasound has the capacity to measure gastric emptying precisely. The use of regression analysis and correlation coefficients, however, may not provide accurate information about the concordance between two methods because $r$ measures the strength of the association, not the agreement. ${ }^{30} 31$ In particular, it would be surprising if methods designed to measure the same quantity were not related. Furthermore, the range of values evaluated influences the correlation but not the agreement. In our study, limits of agreement were approximately $\pm 30 \%$ for the overall group, but less than $\pm 15 \%$ in 10 of the 14 tests. The correlation between ultrasound and scintigraphic measurements of gastric emptying was very close with $r$ values of 0.95 and 0.99 for the two drinks. Holt et al, ${ }^{11}$ Marzio et al, ${ }^{14}$ and Bolondi et al $^{13}$ have reported similar correlations, but estimations of limits of agreement were not performed. Based on our calculations, in the study by Holt et al, ${ }^{11}$ the limits of agreement was approximately $\pm 41 \%$. In the study of Marzio et al ${ }^{14}$ ultrasonographic gastric emptying was substantially faster $(23 \%$ for a milk drink) than scintigraphic measurements. In contrast, in the study by Bolondi et al, ${ }^{13}$ the ultrasound measurement of gastric emptying (T50) was more than $50 \%$ slower than that measured by scintigraphy. These discrepancies are probably attributable to differences in the techniques used to measure gastric emptying ultrasonographically, as the scintigraphic techniques were similar in each study. There was no such discrepancy in our study and the ultrasonographic method used has been shown to have low interobserver variability. ${ }^{32}{ }^{33}$ Previous studies have shown that the intraindividual variation in gastric emptying of liquids in normal subjects is relatively large. ${ }^{22}$ This was confirmed in our study in that the ranges for gastric emptying ( $50 \%$ emptying time) were 13-44 minutes for soup and 37-177 minutes for dextrose. As the limits of agreement for dextrose were about four times greater, the precision of measurement of emptying of low and high nutrient liquids was similar. This indicates that our ultrasonographic method has the capacity, at least in normal subjects, to discriminate between fast and slow emptying of both low and high nutrient liquids.

Our findings therefore confirm the validity of using changes in antral 'size' as a measure of gastric emptying of liquids in normal subjects and show for the first time that this is accounted for by the close correlations between: (a) total stomach emptying and the content of the distal stomach when the latter is expressed as a percentage of its maximum and (b) the changes in antral area measured ultrasonographically and the content of distal stomach measured scintigraphically. The validity of using measurement of antral diameter to evaluate gastric emptying is consistent with the concept that antral tone plays a major part in regulating gastric emptying of liquids ${ }^{6}$ in concert with other factors including the tone of the proximal stomach, antral phasic contractions, pyloric resistance, and proximal small intestinal motility. ${ }^{2}$ However, it should be recognised that a relation between the diameter of the antrum and antral tone has not yet been established. There was a significant, albeit small, discrepancy between ultrasound and scintigraphic measurements of gastric emptying of dextrose, the former being faster at 15 minutes. This may reflect retrograde shift of intragastric content from the distal into the proximal stomach as a result of the stimulation of small intestinal nutrient receptors, ${ }^{34}$ particularly as there was a close concordance between measurements at all time intervals for the low nutrient drink.

In considering the potential clinical utility of ultrasound it should be recognised that ultrasonographic measurement of gastric emptying of solids is technically more complicated and has substantial limitations. ${ }^{35}$ Ultrasound also cannot discriminate between solid and liquid components of the meal. The close concordance between the two methods demonstrated in normal subjects, has to be confirmed in patients with disordered gastric emptying and obviously, ultrasound of the antral region cannot be used after antral resection and also probably other gastric surgery. Ultrasound techniques do, however, have the capacity to measure contractile activity in the distal stomach $^{18}$ and transpyloric flow. ${ }^{16}$

In normal subjects, perception of gastric distension is influenced by gastric tone, ${ }^{36}$ and postprandial sensations of hunger and fullness are probably related to intragastric volume, gastric muscle tension, and feedback from small intestinal nutrient receptors. ${ }^{202436}$ Ingestion of both the low and high nutrient drinks resulted in a decrease in hunger and increase in fullness. The finding of a direct relation between fullness and the retention of the drink in the antrum is consistent with the concept that fullness is related to antral distension. ${ }^{20}$ In previous studies in which an identical meat soup drink was given to patients with functional dyspepsia, postprandial symptoms 
and antral area were greater in the patients when compared with healthy controls. ${ }^{1828} \mathrm{It}$ has also been shown that intragastric meal distribution is frequently abnormal in patients with non-ulcer dyspepsia. ${ }^{29} 37$ In normal subjects gastric distension and small intestinal nutrient stimulation have additive effects to induce nause ${ }^{36}$ and it is probable that both of these mechanisms are important in the aetiology of postprandial symptoms in normal subjects.

This work has been published previously in abstract form: Hveem K, Jones K, Horowitz M, Chatterton BE. Scintigraphic Hveem $K$, Jones $K$, Horowitz $M$, Chatterton BE. Scintigraphic and ultrasonographic measurement of gastric emptying

tionship to appetite. Gastroenterology 1995; 108: A619.
We wish to thank Briony Lane for typing this manuscript.

We wish to thank Briony Lane for typing this manuscript.
This work was supported by a grant from the National Health This work was supported by a grant from the
and Medical Research Council of Australia.

1 Scarpignato C. Gastric emptying measurement in man. In: Scarpignato C, Bianchi Porro G, eds. Clinical investigations of gastric functions. Basel: Karger, 1990: 198-246.

2 Horowitz M, Dent J. Disordered gastric emptying: mechanical basis, assessment and treatment. Baillieres Clin Gastroenterol 1991; 5: 371-407.

3 Maes BD, Hiele MI, Geypens BJ, Rutgeerts PJ, Ghoos YF, Vantrappen G. Pharmacological modulation of gastric emptying rate of solids as measured by the carbon labelled octanoic acid breath test: influence of erythromycin and propantheline. Gut 1994; 35: 333-7.

4 Schwizer W, Maecke H, Fried M. Measurement of gastric emptying by magnetic resonance imaging in humans. Gastroenterology 1992; 103: 369-76.

5 Meeroff JC, Go VLW, Phillips SF. Gastric emptying of liquids in man: quantification by the duodenal recovery marker. Mayo Clin Proc 1973; 48: 728-32.

6 Collins PJ, Horowitz M, Cook DJ, Harding PE, Shearman DJC. Gastric emptying in normal subjects. A reproducible technique using a single scintilation camera and computer system. Gut 1983; 24: 1117-25.

7 Collins PJ, Houghton LA, Read NW, Horowitz M Chatterton $\mathrm{BE}$, Heddle $\mathrm{R}$, et al. Role of proximal and distal stomach in mixed solid and liquid meal emptying. Gut 1991; 32: 615-9.

8 Malbert CH, Mathis C. Antropyloric modulation of transpyloric flow of liquids in pigs. Gastroenterology 1994; 107: 37-46.

9 Bateman DN, Wittingham TA. Measurement of gastric emptying by real-time ultrasound. Gut 1982; 23: 524-7.

10 Holt S, McDicken WN, Anderson T, Stewart IC, Heading RC. Dynamic imaging of the stomach by real-time ultrasound, a method for the study of gastric motility. Gut 1980; 21: 597-601

11 Holt S, Cervantes J, Wilkinson AA, Wallace JHK Measurement of gastric emptying rate in humans by realtime ultrasound. Gastroenterology 1986; 90: 918-23.

12 Bolondi L, Bortolotti M, Santi V, Calletti T, Gaiani S, Labo G. Measurement of gastric emptying time by real-time ultrasonography. Gastroenterology 1985; 89: 752-59.

13 Bolondi L, Santi V, Bortolotti M, Bassi S Li, Turba E. Correlation between scintigraphic and ultrasonographic assessm.

14 Marzio I, Giacobbe A, Conoscitore P. Evaluation of the use of ultrasonography in the study of the liquid gastric use of ultrasonography in the study of the liquid

15 King PM, Adam DR, Pryde A, McKicken WN, Headin RC. Relationship of human antroduodenal motility and transpyloric fluid movement: non-invasive observation with real-time ultrasound. Gut 1984; 25: 1384-91.
16 Hausken T, Ødegård S, Berstad A. Antroduodenal motility and movements of luminal contents studied by duplex sonography. Gastroenterology 1992; 102: 1583-90.

17 Vantrappen G. Methods to study gastric emptying. Dig Dis Sci 1994; 39 (suppl): 915-45.

18 Hausken $T$, Svebak S, Wilhelmsen I, Tangen Haug $T$, Olafsen K, Petterson E, et al. Low vagal tone and antral dysmotility in patients with functional dyspepsia Psychosom Med 1993; 55: 12-22.

19 Hausken T, Berstad A. Wide gastric antrum inpatients with non-ulcer dyspepsia. Effect of cisapride. Scand $\mathfrak{F}$ Gastroenterol 1992; 27: 427-32.

20 Bergmann, Chassany O, Petit A, Triki R, Caulin C, Segrestaa JM. Correlation between echographic gastric emptying and appetite: influence of psyllium. Gut 1992 33: $1042-3$.

21 Hunt JN, Smith JL, Jiang CL. Effect of meal volume and energy density on the gastric emptying of carbohydrates. Gastroenterology 1985; 89: 1326-30.

22 Horowitz M, Edelbroek M, Wishart J, Straathof J. Relationship between oral glucose tolerance and gastric emptying in normal healthy subjects. Diabetologia 1993 36: $857-62$

23 Horowitz M, Jones K, Edelbroek MA, Smout AJ, Read NW. The effect of posture on gastric emptyin and intragastric distribution of oil and aqueous meal components and appetite. Gastroenterology 1993; 105: 382-90.

24 Carney BI, Jones $\mathrm{KL}$, Horowitz M, Sun WM, Penagini R, Meyer JH. Gastric emptying of oil and aqueous meal components in pancreatic insufficiency - effects of posture and ponents in pancreatic insufficiency - effects of post

25 Sepple CP, Read NW. Gastrointestinal correlates for the development of hunger in man. Appetite 1989; 13: 183-91.

26 Greenberg D, Smith GP, Gibbs J. Intraduodenal infusions of fat elicit satiety in the sham feeding rat. Am $\mathcal{f}$ Physiol 1990; 259: R110-8.

27 Gregory PC, McFadyen M, Rayner DV. Duodenal infusion of fat, cholecystokinin secretion and satiety in the pig. Physiol Behav 1989; 45: 1021-4.

28 Hausken T, Berstad A. Effect of nitric oxide on antral motility and symptoms in patients with functional dyspepsia. Scand $\mathcal{F}$ Gastroenterol 1994; 29: 23-8.

29 Troncon LEA Bennett RJM Ahluwalia NK, Thompson DG. Abnormal intragastric distribution of food during gastric emptying in functional dyspepsia patients. Gut 1994; 35: 327-32

30 Bland $M$, Altman DG. Statistical methods for assessing agreement between two methods of clinical measurement. Lancet 1986; i: 307-10.

31 Pollock MA, Jefferson SG, Kane JW, Lomax K, MacKinnon G, Winnard CB. Method comparison - a different approach. Ann Clin Biochem 1992; 29: 556-60.

32 Hveem K, Hausken T, Berstad A. Ultrasonographic assessment of fasting liquid content in human stomach. Scand $\mathcal{F}$ Gastroenterol 1994; 29: 786-9.

33 Irvine $E$ Jan, Tougas $G$, Lappalainen $R$, Bathurst $N$ Reliability and interobserver variability of ultrasonographic measurement of gastric emptying rate Dig Dis $S \mathrm{C}$ 1993; 38: 803-10

34 Edelbroek M, Horowitz M, Maddox AF, Bellen JC. Gastric emptying and intragastric distribution of oil in the presence of a liquid or a solid meal. $f$ Nucl Med 1992; 33: 1283-90.

35 Ricci R, Bontempo I, Corrazziari E, La Bella A, Torsoli A. Real-Time ultrasonography of the gastric antrum. Gut 1993; 34: 173-6.

36 Feinle C, Grundy D, Read NW. Effects of isocaloric duodenal carbohydrate and lipid on gastric motor and sensory responses to gastric distension. Gastroenterology 1995 ; 108: A597.

37 Mangnall YF, Houghton LA, Johnson AG, Read NW. Abnormal distribution of a fatty liquid test meal within the stomach of patients with non-ulcer dyspepsia. Eur $\mathcal{F}$ Gastroenterol Hepatol 1994; 6: 323-7. 